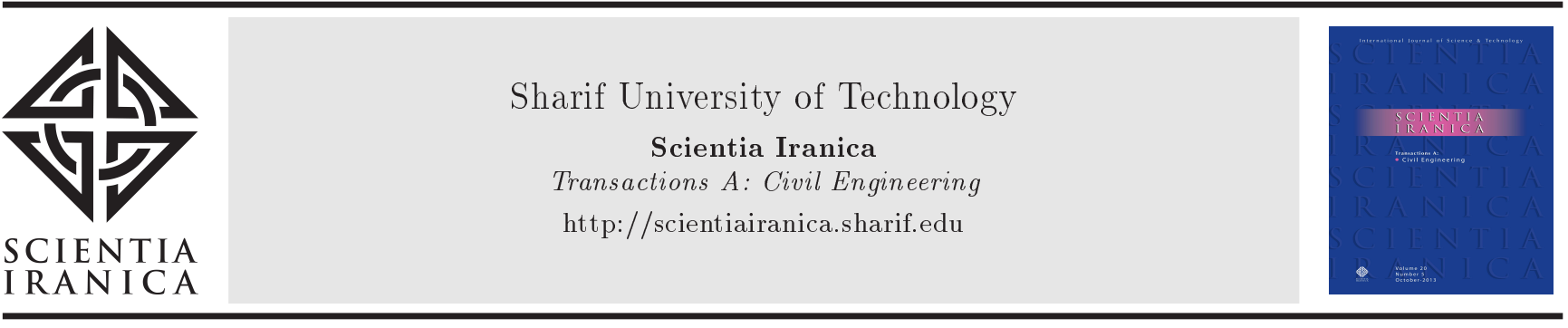

\title{
Shear strength prediction of RC beams using adaptive neuro-fuzzy inference system
}

\author{
H. Naderpour* and M. Mirrashid \\ Faculty of Civil Engineering, Semnan University, Semnan, Iran.
}

Received 20 January 2018; received in revised form 23 February 2018; accepted 21 May 2018

\section{KEYWORDS}

Adaptive Neuro-Fuzzy

Inference System

(ANFIS);

Sub-clustering;

Shear strength;

Reinforced concrete

beams.

\begin{abstract}
In complex engineering problems, there are some inexact conceptions or a lot of parameters that must be considered. Soft computing is an approach that is successfully applied to solve such problems. Determination of fuzzy rules for many problems has not been quite possible by an expert human. In this case, a neuro-fuzzy system that is a combination of neural network (for its ability to learn by datasets) and fuzzy system (for solving the drawback of the neural network) can enhance the performance of the system with several parameters or complex conditions. This paper shows the capability of a neurofuzzy system, namely Adaptive Neuro-Fuzzy Inference System (ANFIS), to predict the shear strength of Reinforced Concrete (RC) beams with steel stirrups. For this purpose, the collection of laboratory results published by different works of literature was used to train and test the proposed system. For this purpose, the Sub-Clustering (SC) approach was applied to generate ANFIS. The results indicated that the considered neuro-fuzzy system was able to predict the shear strength of the RC beams, which have been reinforced with steel stirrups.
\end{abstract}

(C) 2020 Sharif University of Technology. All rights reserved.

\section{Introduction}

A Reinforced Concrete ( $\mathrm{RC})$ beam resists the shear force by several mechanisms such as concrete shear strength (which results from shear compression force and aggregate interlock), vertical reinforcing steel, and shear stirrups. The shear failure of a RC beam is a dangerous brittle failure. Therefore, to prevent this failure, an exact analysis of shear must be considered for the RC element. So far, several experimental research studies have investigated the performance of RC beams to improve the existing relationships presented in common codes such as (ACI 318-14) [1]. In many cases, there is a need for strengthening or retrofitting

\footnotetext{
*. Corresponding author. Tel.: +98 2333533781 ;

Fax: +98 2333654121

E-mail address: naderpour@semnan.ac.ir (H. Naderpour)
}

doi: $10.24200 /$ sci. 2018.50308 .1624 the RC elements. Moreover, sometimes, there is a need to design the members with high shear strength. To this end, Fibre-Reinforced Polymer (FRP) materials have been widely used for reinforcing or strengthening the structural concrete elements such as RC beams $[2,3]$, especially for shear strengthening. There are several guidelines for determining the shear strength of an RC member with FRP such as ACI 440.1 R-15 [4] and CIDAR [5].

The term of soft computing was first defined by Zadeh (1994) [6]. Wilamoski [7] investigated the advantages of soft computing applied in engineering. There are many applications for this type of computational approach in civil engineering for prediction applications such as load forecasting [8] or earthquake magnitude prediction $[9,10]$. In structural engineering, the published works on the prediction of the shear capacity of the RC beams with or without material strengthening were divided into two approaches, which are described in the following section. The first one is 
based on traditional methods, namely hard computing, and the second one is based on soft computing.

\subsection{Prediction based on hard computing}

Hard computing as a computational approach is used to solve problems by such traditional means as statistical methods. By considering hard computing, shear strength in $\mathrm{RC}$ beams was investigated in the last literature such as size effect on the shear strength of RC beams [11]. Mungwa et al. (1999) developed a flexible shear connector using modern fixing techniques based on an experimental study of composite woodconcrete beam with the aim of higher rigidity, ductility, and ultimate strength [12]. Adhikary et al. (2000) predicted the ultimate shear strength of RC beams with epoxy-bonded continuous horizontal steel plates. According to their results, the continuous steel plates that bonded externally to beam webs were effective in shear strengthening [13]. Finite element methods were also used for the analysis of headed stud shear connectors in the steel-concrete composite beam by Lam and El-Lobody (2001) [14].

According to Maru et al. (2003), whereas differential vertical deflections between adjacent vertical members are small owing to high stiffness of beams, the load transfer between them can be significant [15]. Park et al. (2005) proposed a number of relationships to determine the shear strength of the connection between a steel coupling beam and a RC shear wall in a hybrid wall system [16]. Eun et al. (2006) established the shear strength of a RC deep beam with web opening based on eighteen experimental beams, and showed that the load-carrying capacity of deep beams with openings could be largely improved by an increase in concrete strength [17]. Park and Yun (2006) presented certain equations to predict the strength of steel coupling beam-RC shear wall connections [18]. Park and Yun (2006) also investigated the analytical and experimental studies to develop the strength equations of steel coupling beams-concrete wall connections [19]. Kim and LaFave (2007) studied the most important influencing parameters for joint shear behavior using an extensive database of $\mathrm{RC}$ beam-column connection test specimens, exhibiting joint shear failure. They investigated the joint shear cracking stresses and strains by equations and examined the design checks recommended by codes [20]. Ranzi and Zona (2007) presented a model to analyze steel-concrete composite beams with partial shear interaction. The numerical solution was obtained by means of a finite element method, and the numerical results obtained by the proposed model were compared with those of the composite beam model with partial shear interaction in order to determine under which conditions shear deformations of the steel component need to be considered in the analysis and to evaluate how these were affected by the shear connection stiffness [21].

Gara et al. (2009) studied a beam finite element for the long-term analysis of the partial shear interaction at the slab-girder interface using the displacement approach [22]. Jurkiewiez (2009) tested a steel-concrete composite beam, built with a horizontal shear connector under cyclic loading, and showed that the considered connector device allowed satisfactory behavior under static and cyclic loading in accordance with structural modern codes and requirements [23]. Büyükkaragöz and Arslan (2011) investigated the effect of steel plates with shear studs used in the weak column-strong beam connections based on five RC specimens, which were tested under cyclic loading. The test results indicated that the shear studs improved the strength and stiffness of the specimens [24]. Muhsen and Umemura (2011) proposed a model for estimating the shear strength of RC interior beam-column connections. Their results showed that the estimation of shear strength by the new model was favorable [25]. Ramadass and Thomas (2011) studied the details of the flexure-shear analysis of concrete beams reinforced with GFRP bars. Their prediction indicated that the longitudinally FRP-RC beams with no stirrups failed in shear [26]. Doh et al. (2012) developed a nonlinear layered finite element method with the aim of analyzing the punching shear strength of RC flat plate with spandrel beams [27]. Setiawan and Saptono (2012) investigated the capacity of $\mathrm{RC}$ beams with different cross-section types of lateral reinforcement [28]. Shi et al. (2012) analyzed the shear capacity and mechanical properties of deformation comparatively between GFRP-RC beams and steel-RC beams. They also investigated the influencing factors of shear capacity of GFRP-RC beam with circular cross-section, and showed that the influencing coefficient of GFRP on concrete increases with a decrease in the shear span ratio [29].

Gunasekaran et al. (2013) studied the structural shear behavior and shear capacity of the RC beam made with coconut shell and compared their results with the normal control concrete. It was observed that the shear behavior of coconut shell concrete was comparable to that of other lightweight concretes [30]. Houachine et al. (2013) proposed an analytical method, and showed that interfacial shear stresses and pull forces were suitably approximated by using the highorder function of shear deformation [31]. Sung et al. (2013) presented a nonlinear pushover analysis procedure that considers shear failure at beam-column joints, which can be used to estimate the structural behavior of RC frames [32]. Bui et al. (2014) proposed a stressresultant model that combines the descriptions of the diffuse plastic failure in the beam and the localized failure with the creation of the corresponding plastic 
hinges, representing both bending and shear failure mechanisms [33]. Long et al. (2014) investigated those models for simulating beam-column members with a wide range of shear span-to-depth ratios and, also, proposed a method by comparing numerical predictions with experimental results [34].

Manos et al. (2014) studied validation of a numerical model that could approximate the shear behavior of $\mathrm{RC}$ rectangular beams strengthened against shear with externally applied open hoop FRP strips [35]. Yu et al. (2014) tested five pre-stressed steel ultra-high-strength RC beams monotonically until shear failure to study the failure pattern, load-deflection behavior, shear capacity, shear crack width, and shear ductility [36]. Alam et al. (2015) developed Kenaf Fibre-Reinforced Polymer (KFRP) laminate for shear strengthening of $\mathrm{RC}$ beams and proposed designs and theoretical models [37]. Bompa and Elghazouli (2015) examined the shear transfer mechanisms and ultimate behavior of hybrid systems consisting of RC beams connected to structural steel columns [38]. Shahbazpanahi et al. (2015) developed a numerical method for modeling shearstrengthening of the RC beam by FRP composites, and observed that the load capacity increased with the number of CFRP sheets in the shear span [39]. Campione et al. (2015) presented a calculation method to predict the shear resistance of precast composite beams and developed their model on the basis of the results of a referenced experimental campaign of threepoint bending tests [40]. Lu et al. (2015) proposed a joint connecting beam, which is a widely used technology of the mechanic sleeve and sleeve-mortar splicing connections to connect the reinforcement of precast concrete shear walls [41]. Zhang et al. (2015) studied a mechanics-based segmental approach to analyze an $\mathrm{RC}$ beam with any type of concrete and reinforcement based on a segmental approach and, also, proposed a simplified closed-form solution for design [42].

\subsection{Prediction based on soft computing}

Soft computing is an approach that can be realized by experimental or analytical suitable data rather than hard computing. This computational method is used to solve problems with uncertain or complex conditions in multi-dimensional space. It has high accuracy. In concrete structures, there are more parameters that affect analysis or design, and recent studies have indicated that soft computing has been able to function well in structural engineering applications such as the shear strength of RC beams.

Adhikary and Mutsuyoshi (2004) investigated the ability of the multilayer feedforward artificial neural network to predict the ultimate shear capacity of $\mathrm{RC}$ beams with web-bonded steel plates; they showed that Artificial Neural Network (ANN) predicted the ultimate shear capacity of RC beams and cross-validated the results of other models such as a finite element model and analytically empirical models [43]. Adhikary and Mutsuyoshi (2006) predicted the ultimate shear strength of steel fibre RC beams based on a multilayer feed forward neural network with the back propagation learning algorithm. They showed that ANN was able to consider various predictions [44]. The shear resistance of RC beams using neural networks was estimated by Abdalla et al. (2007). This study confirmed that ANN could be used for prediction purposes [45]. Nehdi et al. (2007) used Zsutty equation [46] to optimize the equations of calculating the shear capacity of FRP-RC beams with and without shear reinforcement based on the genetic algorithm [47].

Ahn et al. (2007) investigated the shear force characteristics of steel fiber-RC with varying shapes and mixture ratios using artificial neural networks with backpropagation algorithm, and showed that ANN was a suitable approach to prediction [48]. Perera et al. (2010) applied neural networks to predict the ultimate shear strength of FRP-strengthened RC beams by a database that includes shear strengthened RC beams with FRP using U-jacketing and full wrapping configurations. They also presented design equations to calculate the shear capacity of FRP-strengthened RC beams in shear [49]. Tanarslan (2011) investigated the performance of ANN in predicting the shear capacity of the RC beams retrofitted in shear by means of side-bonded FRP; obtained results demonstrated the higher accuracy of those values obtained by ANN [50]. Tanarslan et al. (2012) used the back propagation network to determine the shear strength contribution of RC beams strengthened in shear by retrofitting externally bonded wrapped and U-jacketed FRP reinforcement, and showed that ANN was a good tool for predicting [51]. Lee and Lee (2014) studied the application of a theoretical approach to predict the shear strength of slender FRP-RC flexural members without stirrups [52]. Nasrollahzadeh and basiri (2014) presented a fuzzy system with Gaussian membership functions and the Takagi-Sugeno inference system using the subtractive clustering algorithm to predict the shear strength of FRP-RC beams. Their fuzzy system was able to predict the shear strength of FRP-RC beams [53]. Perera et al. (2014) proposed formulations of design equations for RC beams shear strengthened with Near Surface Mounted (NSM) FRP rods using artificial neural networks, created by backpropagation and the training algorithm of Levenberg-Marquardt, to predict the capacity of the shear strengthened RC beams with NSM-FRP; their results indicated that the ANN could be used for evaluating the shear capacity of RC members strengthened with NSMFRP [54]. A shear design approach to predicting the contribution of the anchorage FRP reinforcement to the ultimate shear capacity using feed-forward back- 
propagation algorithm was also proposed by Tanarslan et al. (2015) [55]. Furthermore, there are some other investigations based on soft computing methods for estimating the response of concrete structures [56-70].

\subsection{The aim of the study}

Failure under shear of a reinforced beam with longitudinal bars and stirrups in the web may occur by diagonal tension, which is resisted by beam action in the shear span without web reinforcement and also truss mechanism of web reinforcement, generating an additional resisting mechanism to shear for the beam [71].

The shear resistance in a usual RC beam is governed by shear strength of the compression zone (which depends on concrete strength), aggregate interlock, dowel effect of tensile longitudinal bars, and shear reinforcements such as stirrups. Shear forces produce shear stresses [72], and high shear stress generally causes cracks in RC beams. The failure in shear for a RC beam is a mode of failure due to its brittleness. Because of the importance of this failure, it is necessary to consider more investigations, and the current study follows this purpose based on neuro-fuzzy system as a soft computing approach, which has not been applied before.

\section{Adaptive ANFIS}

\subsection{Structure of ANFIS}

ANFIS is a fuzzy inference system for a function approximation problem based on hybrid neuro-fuzzy systems, as introduced by Jang [73]. ANFIS used a Sugeno-type fuzzy system in a five-layer network (the input layer not counted by Jang) for two inputs $x$ and $y$ and one output $z$, as illustrated in Figure 1.

Suppose that the rule base contains two fuzzy ifthen rules of Takagi and Sugeno's types:

- Rule 1: If $x$ is $A_{1}$ and $y$ is $B_{1}$, then $f_{1}=p_{1} x+q_{1} y+r_{1}$ :
- Rule 2: If $x$ is $A_{2}$ and $y$ is $B_{2}$, then $f_{2}=p_{2} x+q_{2} y+$ $r_{2}$.

Then, the corresponding equivalent ANFIS architecture is shown in Figure 1.

The node functions in the same layer are of the same function family as described below [74]:

Layer 1: Every node $i$ in this layer is a square node with a node function as Eq. (1):

$$
O_{i}^{1}=\mu_{A_{i}}(x),
$$

where $x$ is the input to node $i$, and $A_{i}$ is the linguistic label (such as "small" or "large") associated with this node function. In other words, $O_{i}^{1}$ is the membership function of $A_{i}$, and it specifies the degree to which the given $x$ satisfies the quantifier $A_{i}$. Any continuous and piece-wise differentiable functions, such as commonly used bell-shaped, trapezoidal, or triangularshaped membership functions, are qualified candidates for node function in this layer.

Layer 2: Every node in this layer is a circle node labeled II that multiples the incoming signals and sends the product out. For instance:

$$
w_{i}=\mu_{A_{i}}(x) \times \mu_{B_{i}}(y), \quad i=1,2 .
$$

Each node output represents the T-norm operators that combine the possible input membership grades in order to compute the firing strength of a rule.

Layer 3: Every node in this layer is a circle node labeled $N$. The $i$ th node calculates the ratio of the $i$ th rule's firing strength to the sum of all rules' firing strengths:

$$
\bar{w}_{i}=\frac{w_{i}}{w_{1}+w_{2}}, \quad i=1,2 .
$$

For convenience, outputs of this layer will be called normalized firing strengths.

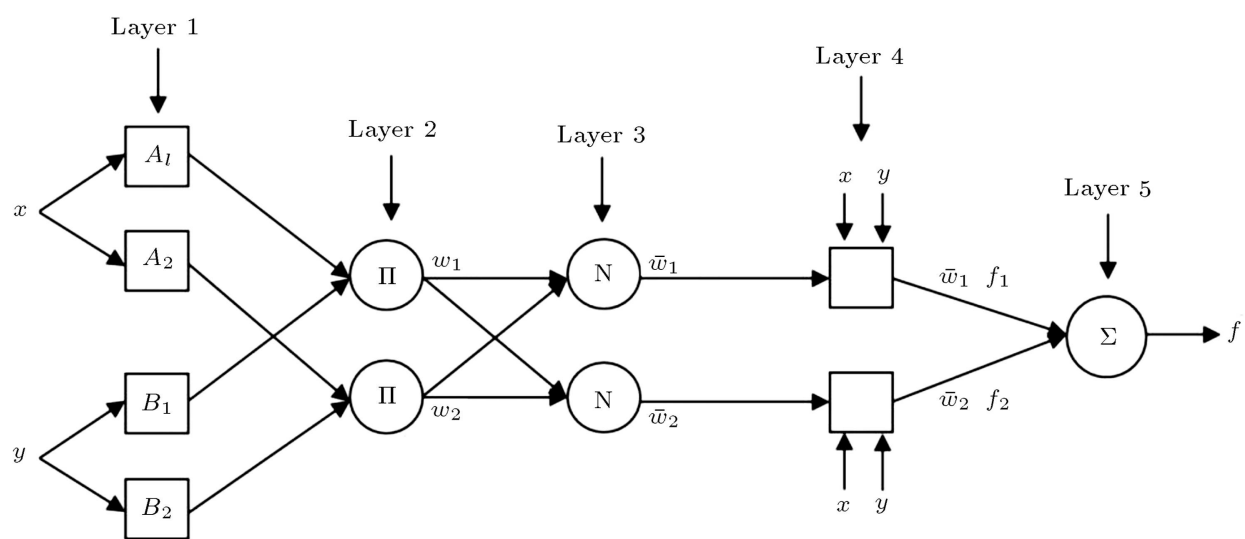

Figure 1. Structure of Adaptive Neuro-Fuzzy Inference System (ANFIS) with 2 inputs and 2 rules. A square node (adaptive node) has parameters, while a circle node (fixed node) has none [24]. 
Layer 4: Every node $i$ in this layer is a square node with a node function:

$$
O_{i}^{4}=\bar{w}_{i} f_{i}=\bar{w}_{i}\left(p_{i} x+q_{i} y+r_{i}\right)
$$

where $\bar{w}_{i}$ is the output of Layer 3 , and $\left\{p_{i}, q_{i}, r_{i}\right\}$ is the parameter set. Parameters in this layer will be referred to as consequent parameters that are adjustable.

Layer 5: The single node in this layer is a circle node (adaptive node) labeled as $\Sigma$ that computes the overall output as a summation of all incoming signals:

$$
O_{i}^{5}=\text { overall output }=\Sigma_{i} \bar{w}_{i} f_{i}=\frac{\Sigma_{i} \bar{w}_{i} f_{i}}{\Sigma_{i} w_{i}}
$$

\subsection{Sub-Clustering (SC) approach}

Clustering is a task of assigning a set of data to groups called clusters to discover structures and patterns in a dataset, and the radius of a cluster is the maximum distance between all the points and the centroid. SubClustering (SC) is based on classifying each point of the dataset just to one cluster and was proposed by Chiu [75]. The SC method assumes that each data point is a potential cluster center and calculates the potential for each data point based on the density of surrounding data points [9]. The measure of the potential for a data point is a function of its distances to all other data points. A data point with many neighboring data points will have a high potential value. The data point with the highest potential is selected as the first cluster center, and the potential of data points near the first cluster center is destroyed. Then, data points with the highest remaining potential as the next cluster center and the potential of data points near the new cluster center are destroyed [9]. It is notable that the influential radius of the cluster is critical for determining the number of clusters, and the data points outside this radius have insignificant influence on the potential. In addition, a smaller radius leads to many smaller clusters in the data space, resulting in more rules [75].

\section{Database}

ANFIS requires a dataset for training. It is mentioned that the ability of a system such as ANN or ANFIS depends on the data used in training or validation phase. In this paper, the collection of 194 experimental results, published in the literature, was applied to train and test the ANFIS [76-93]. A summary of the dataset is presented in Table 1 . The parameters in this table include width of the member $(b)$, effective depth of the member $(d)$, concrete compressive strength $\left(f_{c o}\right)$, the yielding strength of transverse reinforcement $\left(f_{s y}\right)$, the yielding strength of longitudinal reinforcement $\left(f_{r y}\right)$, web cross-sectional area of the reinforcement as a proportion of the cross-sectional area of the beam $\left(\rho_{r t}\right)$, the transverse reinforcement ratio $\left(\rho_{s t}\right)$, and the experimental shear strength $(V)$.

To classify the interval of values that are different on the same scale, a normalizing procedure was used. A simple normalization relationship within a value of 0.1 to 0.9 , which is used for normalization in this paper, is Eq. (6):

$$
x_{i}=0.8 \frac{x-x_{\min }}{x_{\max }-x_{\min }}+0.1
$$

where $x_{i}$ is the normalized value of a certain parameter, $x$ is the measured value for this parameter, and $x_{\min }$ and $x_{\max }$ are the minimum and maximum values in the database for this parameter, respectively.

In order to use the proposed ANFIS in this paper and in accordance with Eq. (6), the minimum and maximum values of each variable are required to calculate its normal value ( 0.1 to 0.9 in this paper). These amounts can be extracted from Table 1 and used in the determination process of the ANFIS. The other details such as mean or average were also presented to gain knowledge of the applied database.

\section{The proposed ANFIS model}

\subsection{Properties of the model}

First, the datasets are divided into training data, consisting of 160 pairs of inputs and outputs, and test

Table 1. Range of experimental data.

\begin{tabular}{lccccc}
\hline & Mean & Average & Minimum & Maximum & $\begin{array}{c}\text { Standard } \\
\text { deviation }\end{array}$ \\
\hline$b(\mathrm{~mm})$ & 203.00 & 207.40 & 76.00 & 457.00 & 81.49 \\
$d(\mathrm{~mm})$ & 383.00 & 358.88 & 95.00 & 851.00 & 129.31 \\
$f_{c o}(\mathrm{MPa})$ & 28.00 & 29.60 & 12.80 & 50.30 & 7.20 \\
$f_{s y}(\mathrm{MPa})$ & 331.00 & 384.09 & 159.00 & 820.00 & 123.15 \\
$f_{r y}(\mathrm{MPa})$ & 434.00 & 459.80 & 300.00 & 707.00 & 131.10 \\
$\rho_{r t}$ & 2.70 & 2.72 & 1.00 & 4.80 & 0.91 \\
$\rho_{s t}$ & 0.30 & 0.36 & 0.10 & 1.90 & 0.26 \\
$V(\mathrm{kN})$ & 214.00 & 252.96 & 13.60 & 836.10 & 163.96 \\
\hline
\end{tabular}


data with 34 pairs. In this study, ANFIS with seven parameters includes width of the member, effective depth of the member, concrete compressive strength, the yielding strength of transverse reinforcement, the yielding strength of longitudinal reinforcement, web cross-sectional area of the reinforcement as a proportion of the cross-sectional area of the beam, and also the transverse reinforcement ratio used for predicting the shear strength of $\mathrm{RC}$ beams with steel stirrups. The range of influence was considered as 0.6 (to specify a cluster center' range of influence in each data dimension) and the squash factor (the factor to multiply the range of influence that determines the neighborhood of a cluster) as 1.25. The acceptance ratio (the factor that sets the potential as a fraction of the potential of the first cluster center, above which another data point is accepted as a cluster center) and rejection ratio (the factor that sets the potential as a fraction of the potential of the first cluster center, below which another data point is accepted as a cluster center) were 0.5 and 0.15 , respectively.

\subsection{Membership functions and clusters}

ANFIS based on SC approach used a Gaussian membership function (Figure 2) for input parameters, shown in Figures 3-9, as follows:

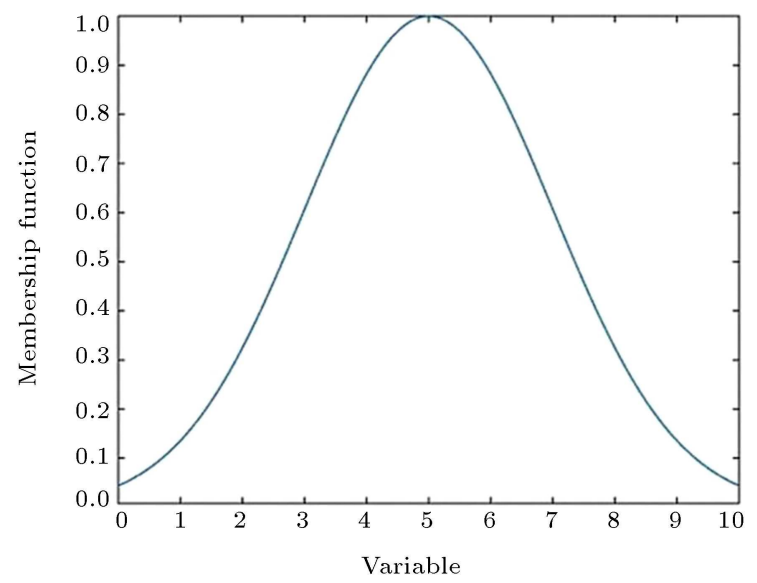

Figure 2. Gaussian membership function with the median and variance of 5 and 2, respectively.

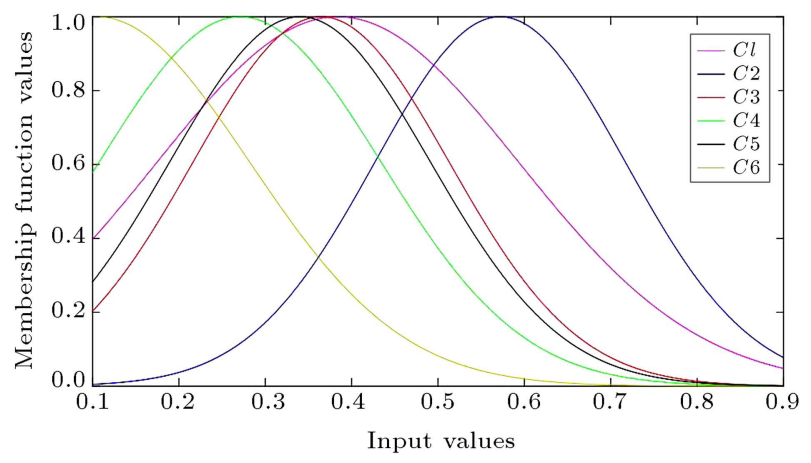

Figure 3. Membership functions for " $b$ ".

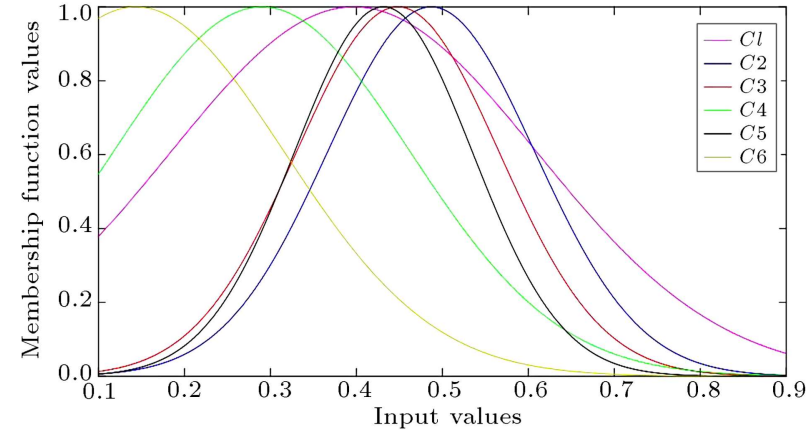

Figure 4. Membership functions for " $d$ ".

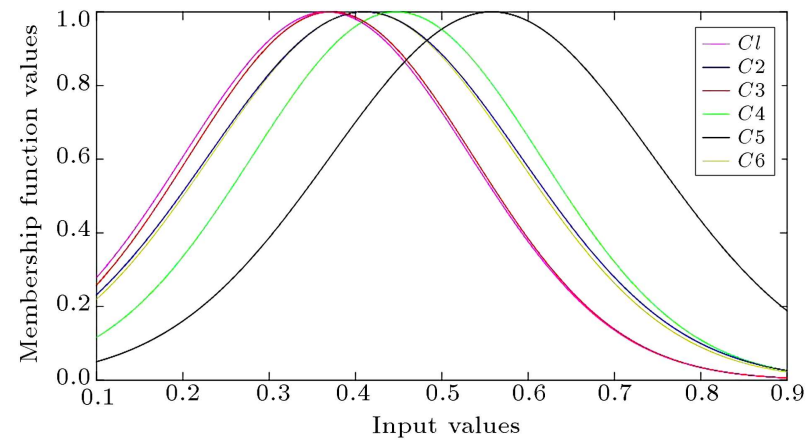

Figure 5. Membership functions for " $f_{c o}$ ".

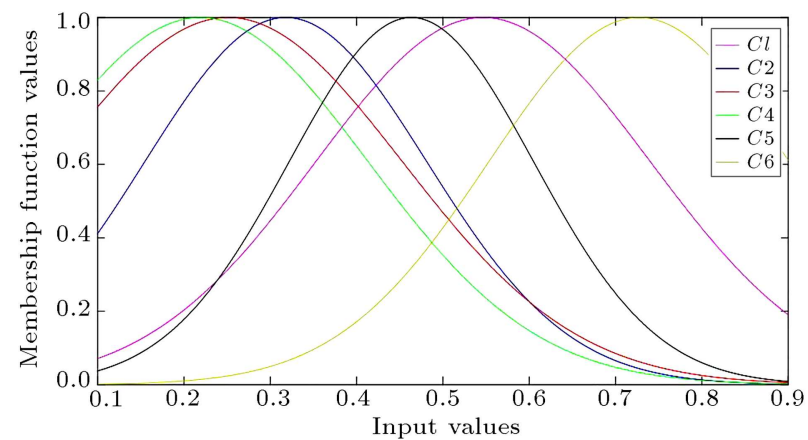

Figure 6. Membership functions for " $\rho_{r t}$ ".

$$
\mu(x ; \sigma, c)=e^{\frac{-(x-c)^{2}}{2 \sigma^{2}}},
$$

where $c$ is the mean and $\sigma$ is the variance for $x$.

It is mentioned that two parameters including $\sigma$ and $c$ are required to define this type of membership function. For each input, six Gaussian membership functions were used, whose details are presented in Table 2. The parameters of clusters $(C L)$ are also shown in Table 3 . These parameters consider the output's equations (Eq. (8)) that are used to calculate the shear strength based on Eq. (4). The final ANFIS structure is illustrated in Figure 10.

$$
C L_{j}=a_{1} x_{1}+a_{2} x_{2}+a_{3} x_{3}+C, \quad j=1, . ., 6 .
$$

The parameters $a_{1}, \cdots, a_{7}$ are coefficients of the input $x_{1}, \cdots, x_{7}$. Parameter $C$ deals with a constant value. The amounts of these parameters are presented in Table 3 . 


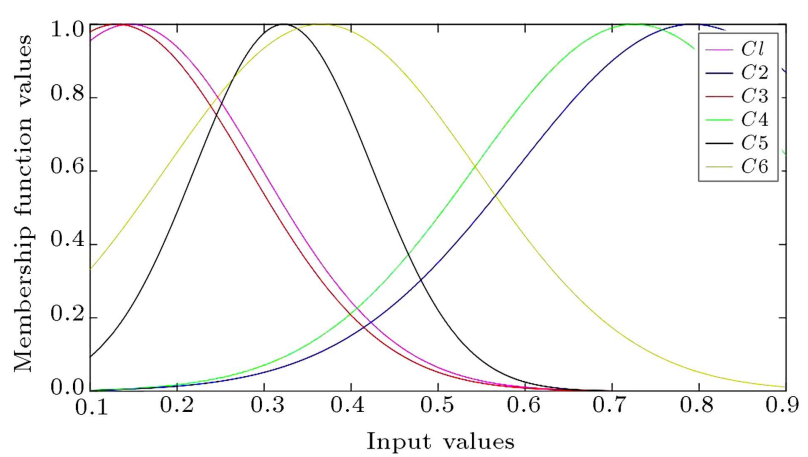

Figure 7. Membership functions for " $f_{r y}$ ".

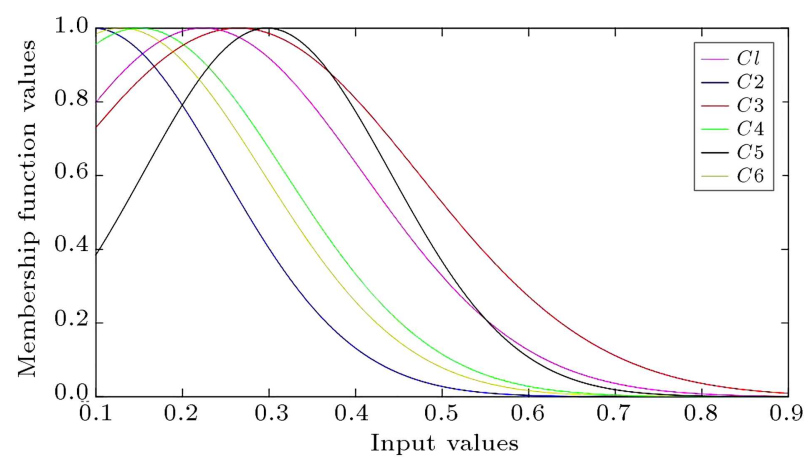

Figure 8. Membership functions for " $\rho_{s t}$ ".

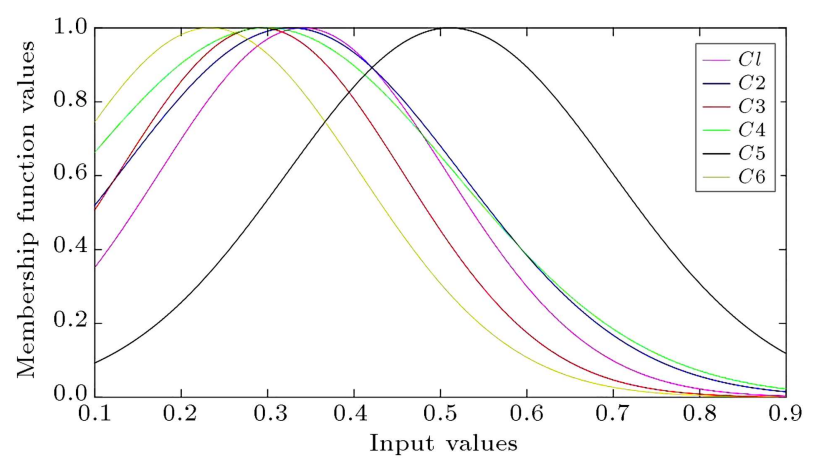

Figure 9. Membership functions for " $f_{s y}$ ".

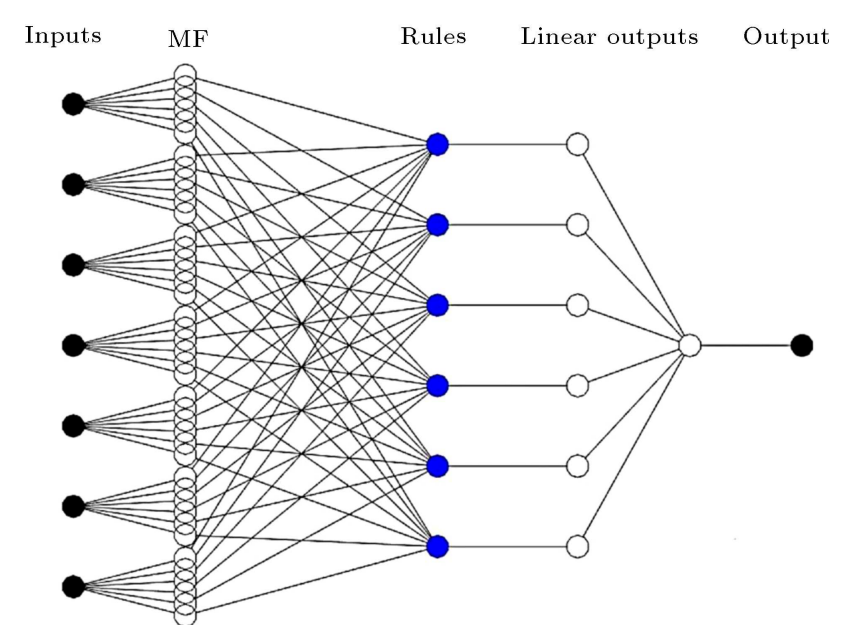

Figure 10. The proposed Adaptive Neuro-Fuzzy Inference System (ANFIS) structure.

\subsection{Rules}

In this study, first, several ANFIS models with different approaches and parameters were created; finally, the best of them were considered. The selected model generated based on the subtractive clustering method used six simple rules including:

Rule 1: If " $b$ " is $C 1$ and " $d$ " is $C 1$ and " $f_{c o}$ " is $C 1$ and " $\rho_{r t}$ " is $C 1$ and " $f_{r y}$ " is $C 1$ and " $\rho_{s t}$ " is $C 1$ and " $f_{s y}$ " is $C 1$, then " $V$ " is in Cluster 1 ;

Rule 2: If " $b$ " is $C 2$ and " $d$ " is $C 2$ and " $f_{c o}$ " is $C 2$ and " $\rho_{r t}$ " is $C 2$ and " $f_{r y}$ " is $C 2$ and " $\rho_{s t}$ " is $C 2$ and " $f_{s y}$ " is $C 2$, then " $V$ " is in Cluster 2;

Rule 3: If " $b$ " is $C 3$ and " $d$ " is $C 3$ and " $f_{c o}$ " is $C 3$ and " $\rho_{r t}$ " is $C 3$ and " $f_{r y}$ " is $C 3$ and " $\rho_{s t}$ " is $C 3$ and " $f_{s y}$ " is $C 3$, then " $V$ " is in Cluster 3 ;

Rule 4: If " $b$ " is $C 4$ and " $d$ " is $C 4$ and " $f_{c o}$ " is $C 4$ and " $\rho_{r t}$ " is $C 4$ and " $f_{r y}$ " is $C 4$ and " $\rho_{s t}$ " is $C 4$ and " $f_{s y}$ " is $C 4$, then " $V$ " is in Cluster 4 ;

Rule 5: If " $b$ " is $C 5$ and " $d$ " is $C 5$ and " $f_{c o}$ " is $C 5$ and " $\rho_{r t}$ " is $C 5$ and " $f_{r y}$ " is $C 5$ and " $\rho_{s t}$ " is $C 5$ and " $f_{s y}$ " is $C 5$, then " $V$ " is in Cluster 5;

Rule 6: If " $b$ " is C6 and " $d$ " is $C 6$ and " $f_{c o}$ " is $C 6$ and " $\rho_{r t}$ " is $C 6$ and " $f_{r y}$ " is $C 6$ and " $\rho_{s t}$ " is $C 6$ and " $f_{s y}$ " is $C 6$, then " $V$ " is in Cluster 6 .

\subsection{Final ANFIS output}

Based on the rule base presented in the previous section, the rule's weight $W$ for each of the six rules can be calculated as follows:

$$
\begin{aligned}
W_{1}= & \left(C 1_{X 1}\right) \times\left(C 1_{X 2}\right) \times\left(C 1_{X 3}\right) \times\left(C 1_{X 4}\right) \\
& \times\left(C 1_{X 5}\right) \times\left(C 1_{X 6}\right) \\
W_{2}= & \left(C 2_{X 1}\right) \times\left(C 2_{X 2}\right) \times\left(C 2_{X 3}\right) \times\left(C 2_{X 4}\right) \\
& \times\left(C 2_{X 5}\right) \times\left(C 2_{X 6}\right) \\
W_{3}= & \left(C 3_{X 1}\right) \times\left(C 3_{X 2}\right) \times\left(C 3_{X 3}\right) \times\left(C 3_{X 4}\right) \\
& \times\left(C 3_{X 5}\right) \times\left(C 3_{X 6}\right) \\
W_{4}= & \left(C 4_{X 1}\right) \times\left(C 4_{X 2}\right) \times\left(C 4_{X 3}\right) \times\left(C 4_{X 4}\right) \\
& \times\left(C 4_{X 5}\right) \times\left(C 4_{X 6}\right) \\
W_{5}= & \left(C 5_{X 1}\right) \times\left(C 5_{X 2}\right) \times\left(C 5_{X 3}\right) \times\left(C 5_{X 4}\right) \\
& \times\left(C 5_{X 5}\right) \times\left(C 5_{X 6}\right),
\end{aligned}
$$


Table 2. Parameters of the membership functions for each of the inputs.

\begin{tabular}{|c|c|c|c|c|c|c|c|c|c|c|c|c|}
\hline \multirow{3}{*}{$\frac{\text { Input }}{b(\mathrm{~mm})}$} & \multicolumn{12}{|c|}{ Membership functions } \\
\hline & \multicolumn{2}{|c|}{$C 1$} & \multicolumn{2}{|c|}{$C 2$} & \multicolumn{2}{|c|}{ C3 } & \multicolumn{2}{|c|}{$C 4$} & \multicolumn{2}{|c|}{$C 5$} & \multicolumn{2}{|c|}{$C 6$} \\
\hline & 0.21 & 0.38 & 0.14 & 0.57 & 0.15 & 0.36 & 0.16 & 0.27 & 0.15 & 0.34 & 0.18 & 0.11 \\
\hline$d(\mathrm{~mm})$ & 0.21 & 0.40 & 0.12 & 0.49 & 0.12 & 0.45 & 0.17 & 0.29 & 0.10 & 0.43 & 0.17 & 0.14 \\
\hline$f_{c o}(\mathrm{MPa})$ & 0.17 & 0.37 & 0.17 & 0.40 & 0.16 & 0.37 & 0.17 & 0.45 & 0.19 & 0.56 & 0.18 & 0.41 \\
\hline$\rho_{r t}$ & 0.19 & 0.55 & 0.16 & 0.32 & 0.20 & 0.25 & 0.19 & 0.22 & 0.14 & 0.46 & 0.17 & 0.73 \\
\hline$f_{r y}$ & 0.15 & 0.15 & 0.20 & 0.79 & 0.15 & 0.13 & 0.18 & 0.73 & 0.10 & 0.32 & 0.18 & 0.36 \\
\hline$\rho_{s t}$ & 0.18 & 0.22 & 0.15 & 0.10 & 0.21 & 0.26 & 0.17 & 0.15 & 0.14 & 0.30 & 0.16 & 0.13 \\
\hline$f_{s y}$ & 0.17 & 0.34 & 0.20 & 0.33 & 0.17 & 0.29 & 0.22 & 0.30 & 0.19 & 0.51 & 0.17 & 0.23 \\
\hline
\end{tabular}

Table 3. Parameters of the output's clusters.

\begin{tabular}{llccccc}
\hline & \multicolumn{7}{c}{ Clusters $(\mathbf{C L})$} \\
\cline { 2 - 7 } Parameter & $\mathbf{1}$ & $\mathbf{2}$ & $\mathbf{3}$ & $\mathbf{4}$ & $\mathbf{5}$ & $\mathbf{6}$ \\
\hline$a_{1}$ : Coefficient of $b$ & 1.0960 & 0.9559 & 0.4386 & 0.7244 & 2.3590 & 1.9460 \\
$a_{2}$ : Coefficient of $d$ & 0.4803 & 1.3460 & -4.4590 & 0.2059 & 1.3620 & -1.3860 \\
$a_{3}$ : Coefficient of $f_{c o}$ & -0.0359 & -0.1656 & 0.3612 & 0.0348 & 0.3841 & 0.0550 \\
$a_{4}$ : Coefficient of $\rho_{r t}$ & 1.6890 & 0.4570 & 1.6600 & 0.1079 & 0.2317 & -0.7271 \\
$a_{5}:$ Coefficient of $f_{r y}$ & -0.8179 & -0.0567 & 2.2690 & 0.1138 & -1.1040 & -0.1055 \\
$a_{6}$ : Coefficient of $\rho_{s t}$ & 0.3102 & 1.6790 & -0.3096 & 0.1445 & 0.6772 & 0.1339 \\
$a_{7}$ : Coefficient of $f_{s y}$ & 0.2422 & -0.3519 & 0.1526 & 0.4228 & 0.0046 & 0.0437 \\
$c:$ Coefficient of constant & -1.4060 & -1.003 & 1.4790 & -0.3252 & -1.0520 & 0.6370 \\
\hline
\end{tabular}

$$
\begin{aligned}
W_{6}= & \left(C 6_{X 1}\right) \times\left(C 6_{X 2}\right) \times\left(C 6_{X 3}\right) \times\left(C 6_{X 4}\right) \\
& \times\left(C 6_{X 5}\right) \times\left(C 6_{X 6}\right) .
\end{aligned}
$$

The normal value of the shear strength $\left(V_{n}\right)$ based on the ANFIS model can be determined by Eq. (9). It is worth noting that the output of Eq. (9) can be easily converted to the real value based on Eq. (6) and the amount values of Table 1 (the minimum and maximum of the output parameter).

$$
V_{n}=\frac{\sum_{j=1}^{6} w_{\mathrm{Rule}, j} C L_{j}}{\sum_{j=1}^{6} w_{\mathrm{Rule}, j}} .
$$

\section{Results}

\subsection{ANFIS results}

After generating ANFIS, it was trained with considered 160 pairs of inputs-output based on selected conditions, as presented in previous sections. Figure 11 shows the training process, indicating that the ANFIS reached its minimum error at less than 50 epochs. The outputs of the ANFIS against experimental data (normalized values between 0.1 to 0.9 ) are presented in Figure 12. Based on the figure, ANFIS has a good performance in the training phase. The selected neuro-fuzzy also predicted the shear strength of $\mathrm{RC}$ beams with steel stirrups, too (Figure 13).

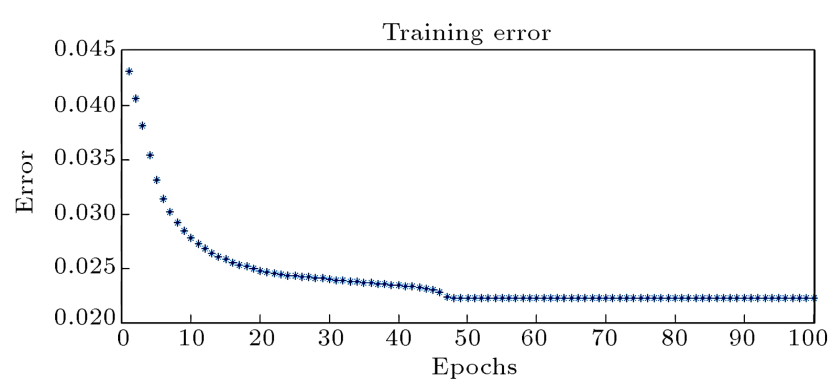

Figure 11. The training process.

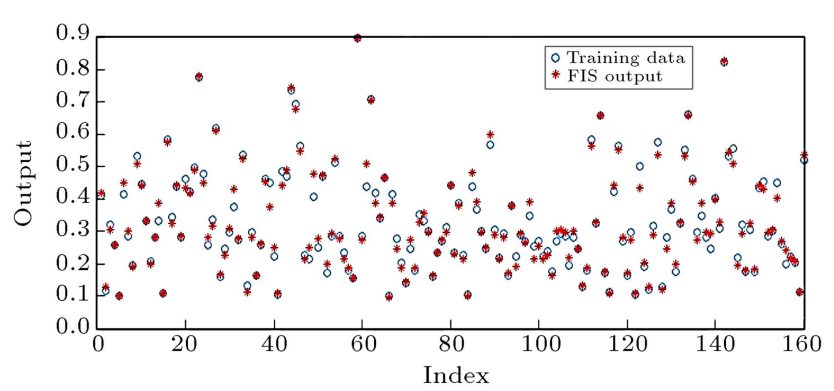

Figure 12. The training results of Adaptive Neuro-Fuzzy Inference System (ANFIS).

The proposed ANFIS in this paper has a correlation coefficient $\left(R^{2}\right)$ equal to 0.98 and 0.94 in training and test phases, respectively. These values are clearly shown in Figures 14 and 15. It is important that the selected data for training cover all of the ranges of shear 
Table 4. Distribution of error for the proposed Adaptive Neuro-Fuzzy Inference System (ANFIS) based on experimental data.

\begin{tabular}{cccccc}
\hline \multirow{2}{*}{$\begin{array}{c}\text { Range of } \\
\text { error }(\%)\end{array}$} & $\begin{array}{c}\text { Number of data in the } \\
\text { range of ANFIS }\end{array}$ & & \multicolumn{2}{c}{$\begin{array}{c}\text { Percentage of } \\
\text { whole data for }\end{array}$} \\
\cline { 2 - 3 } \cline { 5 - 6 } & Train data & Test data & & Train data & Test data \\
\hline$< \pm 5$ & 65 & 12 & & 40.62 & 35.29 \\
$< \pm 10$ & 112 & 22 & & 70.00 & 64.70 \\
$< \pm 15$ & 133 & 26 & & 83.12 & 76.47 \\
$< \pm 20$ & 143 & 27 & & 89.37 & 79.41 \\
$< \pm 25$ & 153 & 28 & & 95.62 & 82.35 \\
$< \pm 30$ & 156 & 28 & & 97.50 & 82.35 \\
$< \pm 35$ & 157 & 29 & & 98.12 & 85.29 \\
$< \pm 40$ & 158 & 30 & & 98.75 & 88.23 \\
$< \pm 45$ & 160 & 31 & & 100.00 & 91.17 \\
$> \pm 45$ & 0 & 3 & & 0.00 & 0.08 \\
\hline
\end{tabular}

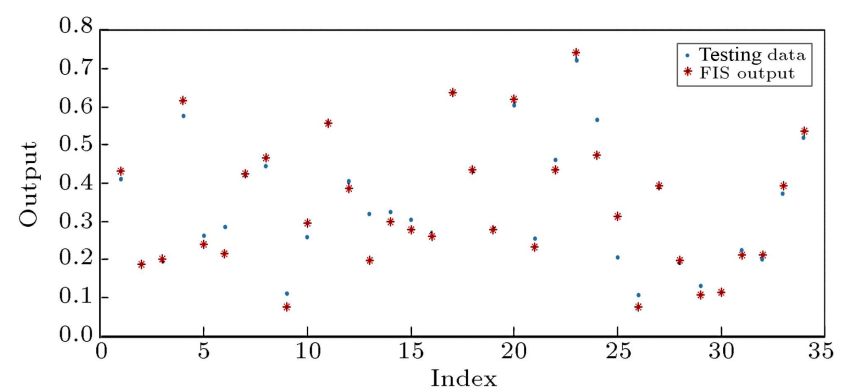

Figure 13. The test results of Adaptive Neuro-Fuzzy Inference System (ANFIS).

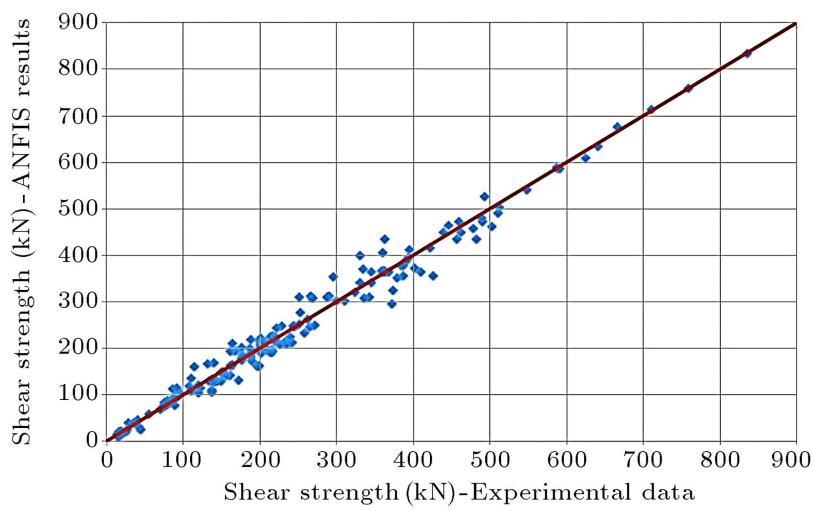

Figure 14. The results of Adaptive Neuro-Fuzzy Inference System (ANFIS) for the training phase.

values. This is due to an increase in the accuracy of the ANFIS.

\subsection{Error calculations and correlation coefficient values}

The details of results of the ANFIS have included one point in the training (0.097) and two points in the test $(0.074,0.076)$, having values less than 0.1 . These amounts lead to negative values after converting them to real values (based on Eq. (6). To avoid this, it is

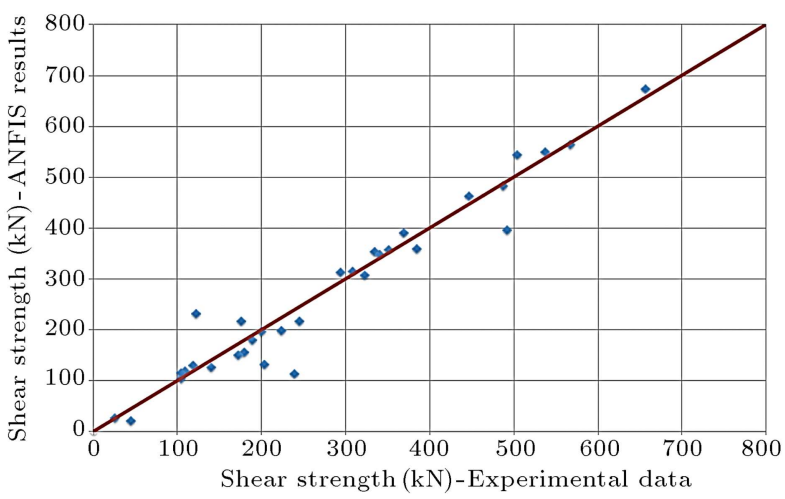

Figure 15. The results of Adaptive Neuro-Fuzzy Inference System (ANFIS) for test data.

assumed that they correspond with 0.1. Because these amounts are so close to 0.1 , the considered assumption can be suitable. Table 4 presents the final results after converting them to the whole 160 training data and 34 test data. A comparison between the results of the proposed ANFIS and other codes for $\frac{V_{\text {test }}}{V_{A N F I S}}$ ratio showed a value equal to 0.998 for ANFIS, while it is equal to $1.88,1.48,1.37$ for ACI 318-08, CSA A23.304, and CEN 2004, respectively.

\section{Conclusion}

In this paper, a neuro-fuzzy system called Adaptive Neuro-Fuzzy Inference System (ANFIS) was proposed to predict the shear strength of Reinforced Concrete (RC) beams with steel stirrups using seven parameters including the width of the member, effective depth of the member, concrete compressive strength, the yielding strength of transverse reinforcement, the yielding strength of longitudinal reinforcement, web crosssectional area of the reinforcement as a proportion of the cross-sectional area of the beam, and also the 
transverse reinforcement ratio. ANFIS requires a database to determine its value. It was mentioned that a collection of more data could directly affect the results of ANFIS and lead to a model with high accuracy. In this paper, ANFIS was generated by the subtractive clustering method and trained with 160 data, as collected from the literature based on experimental data. Afterward, the neuro-fuzzy model was examined to specify the capability of ANFIS; for this purpose, 34 data were considered. The final results indicated that ANFIS could be used to predict the shear strength of RC beams with suitable accuracy. ANFIS is a powerful tool for determining the values of parameters in multi-dimensional space with uncertain conditions. As a result, there are many types of research in civil engineering that have been done, and the current paper presented another application of this neuro-fuzzy system.

\section{References}

1. American Concrete Institute, Building Code Requirements for Structural Concrete (ACI 318-14): Commentary on Building Code Requirements for Structural Concrete (ACI 318R-14): An ACI Report, American Concrete Institute, ACI (2014).

2. Li, W. and Leung, C.K.Y. "Shear span-depth ratio effect on behavior of RC beam shear strengthened with full-wrapping FRP strip", Journal of Composites for Construction, 20(3), 04015067 (2016).

3. Taleb, S.A. and Salem, A.S. "Bending and shear behavior of a composite beam strengthened and doubleconfined with FRP-Jacket", Procedia Engineering, 114, pp. 165-172 (2015).

4. ACI Committee 440, Guide for the Design and Construction of structural concrete reinforced with Fiber Reinforced Polymer (FRP) bars (ACI 440.1 R-15), Farmington Hills, MI: American Concrete Institute (2015).

5. "CIDAR, Design guideline for RC structures retrofitted with FRP and metal plates: beams and slab", Submitted To Standards Australia, The University of Adelaide (2006).

6. Zadeh, L.A. "Fuzzy logic, neural networks, and soft computing", Communications of the ACM, 37(3), pp. 77-84 (1994).

7. Wilamowski, B.M. "Advantages and problems of soft computing", In Industrial Informatics (INDIN), 9th IEEE International Conference on, pp. 5-11 (2011).

8. Raza, M.Q. and Baharudin, Z. "A review on short term load forecasting using hybrid neural network techniques", In Power and Energy (PECon), IEEE International Conference on, pp. 846-851 (2012).
9. Mirrashid, M. "Earthquake magnitude prediction by adaptive neuro-fuzzy inference system (ANFIS) based on fuzzy C-means algorithm", Natural Hazards, 74(3), pp. 1577-1593 (2014).

10. Mirrashid, M., Givehchi, M., Miri, M., and Madandoust, R. "Performance investigation of neuro-fuzzy system for earthquake prediction", Asian Journal of Civil Engineering (BHRC), 17(2), pp. 213-223 (2016).

11. Shioya, T. and Kawasaki, H. "Size effect on shear strength of reinforced concrete beam", In Finite Element Analysis of Reinforced Concrete Structures, pp. 255-264 (1985).

12. Mungwa, M.S., Jullien, J.-F., Foudjet, A., and Hentges, G. "Experimental study of a composite wood-concrete beam with the INSA-Hilti new flexible shear connector", Construction and Building Materials, 13(7), pp. 371-382 (1999).

13. Adhikary, B.B., Mutsuyoshi, H., and Sano, M. "Shear strengthening of reinforced concrete beams using steel plates bonded on beam web: experiments and analysis", Construction and Building Materials, 14(5), pp. 237-244 (2000).

14. Lam, D. and El-Lobody, E. "Finite element modelling of headed stud shear connectors in steel-concrete composite beam", Proceedings of the International Conference on Structural Engineering, Mechanics and Computation, Elsevier Science, South Africa, 1, pp. 401-408 (2001).

15. Maru, S., Sharma, R., and Nagpal, A. "Effect of creep and shrinkage in reinforced concrete frame-shear wall system with high beam stiffness", The Structural Design of Tall and Special Buildings, 12(2), pp. 93-108 (2003).

16. Park, W.-S., Yun, H.-D., Hwang, S.-K., Han, B.C., and Yang, I.S. "Shear strength of the connection between a steel coupling beam and a reinforced concrete shear wall in a hybrid wall system", Journal of Constructional Steel Research, 61(7), pp. 912-941 (2005).

17. Eun, H.C., Lee, Y.H., Chung, H.S., and Yang, K.H. "On the shear strength of reinforced concrete deep beam with web opening", The Structural Design of Tall and Special Buildings, 15(4), pp. 445-466 (2006).

18. Park, W.-S. and Yun, H.-D. "The bearing strength of steel coupling beam-reinforced concrete shear wall connections", Nuclear Engineering and Design, 236(1), pp. 77-93 (2006).

19. Park, W.-S. and Yun, H.-D. "Bearing strength of steel coupling beam connections embedded reinforced concrete shear walls", Engineering Structures, 28(9), pp. 1319-1334 (2006).

20. Kim, J. and LaFave, J.M. "Key influence parameters for the joint shear behaviour of reinforced concrete (RC) beam-column connections", Engineering Structures, 29(10), pp. 2523-2539 (2007). 
21. Ranzi, G. and Zona, A. "A steel-concrete composite beam model with partial interaction including the shear deformability of the steel component", Engineering Structures, 29(11), pp. 3026-3041 (2007).

22. Gara, F., Leoni, G., and Dezi, L. "A beam finite element including shear lag effect for the time-dependent analysis of steel-concrete composite decks", Engineering Structures, 31(8), pp. 1888-1902 (2009).

23. Jurkiewiez, B. "Static and cyclic behaviour of a steelconcrete composite beam with horizontal shear connections", Journal of Constructional Steel Research, 65(12), pp. 2207-2216 (2009).

24. Büyükkaragöz, A. and Arslan, A. "The effect of steel plates with shear studs for weak column-strong beam connections in the reinforced concrete structures under earthquake effect", Strain, 47(s2), pp. 393-411 (2011).

25. Muhsen, B.A. and Umemura, H. "New model for estimation of shear strength of reinforced concrete interior beam-column joints", Procedia Engineering, 14 pp. 2151-2159 (2011).

26. Ramadass, S. and Thomas, J. "Flexure-shear analysis of concrete beam reinforced with GFRP bars", In Advances in FRP Composites in Civil Engineering, Springer, pp. 321-324 (2011).

27. Doh, J.H., Guan, H., and Kim, T. "Parametric and comparative study of spandrel beam effect on the punching shear strength of reinforced concrete flat plates", The Structural Design of Tall and Special Buildings, 21(8), pp. 605-620 (2012).

28. Setiawan, A. and Saptono, K. "Shear capacity of reinforced concrete beam with different cross section types of lateral reinforcement on minimum ratio", Procedia Engineering, 50, pp. 576-585 (2012).

29. Shi, X.-q., Zhang, Z.-q., and Li, Z.-y. "Experimental study of the shear capacity of glass fiber reinforced polymer reinforced concrete beam with circular cross section", Journal of Shanghai Jiaotong University (Science), 17, pp. 408-414 (2012).

30. Gunasekaran, K., Annadurai, R., and Kumar, P. "Study on reinforced lightweight coconut shell concrete beam behavior under shear", Materials and Design, 50, pp. 293-301 (2013).

31. Houachine, H., Sereir, Z., Kerboua, B., and Hadjazi, K. "Combined cohesive-bridging zone model for prediction of the debonding between the FRP and concrete beam interface with effect of adherend shear deformations", Composites Part B: Engineering, 45(1), pp. 871-880 (2013).

32. Sung, Y., Lin, T., Hsiao, C., and Lai, M. "Pushover analysis of reinforced concrete frames considering shear failure at beam-column joints", Earthquake Engineering and Engineering Vibration, 12(3), pp. 373-383 (2013).
33. Bui, N., Ngo, M., Nikolic, M., Brancherie, D., and Ibrahimbegovic, A. "Enriched Timoshenko beam finite element for modeling bending and shear failure of reinforced concrete frames", Computers \& Structures, 143, pp. 9-18 (2014).

34. Long, X., Bao, J., Tan, K., and Lee, C. "Numerical simulation of reinforced concrete beam/column failure considering normal-shear stress interaction", Engineering Structures, 74, pp. 32-43 (2014).

35. Manos, G., Theofanous, M., and Katakalos, K. "Numerical simulation of the shear behaviour of reinforced concrete rectangular beam specimens with or without FRP-strip shear reinforcement", Advances in Engineering Software, 67, pp. 47-56 (2014).

36. Yu, F., Yao, D., Jia, J., and Wu, F. "Shear behavior of novel prestressed concrete beam subjected to monotonic and cyclic loading", Transactions of Tianjin University, 20, pp. 257-265 (2014).

37. Alam, M.A., Hassan, A., and Muda, Z.C. "Development of kenaf fibre reinforced polymer laminate for shear strengthening of reinforced concrete beam", Materials and Structures, 49(3), pp. 795-811 (2016).

38. Bompa, D. and Elghazouli, A. "Ultimate shear behaviour of hybrid reinforced concrete beam-to-steel column assemblages", Engineering Structures, 101, pp. 318-336 (2015).

39. Shahbazpanahi, S., Ali, A.A.A., Kamgar, A., and Farzadnia, N. "Fracture mechanic modeling of fiber reinforced polymer shear-strengthened reinforced concrete beam", Composites Part B: Engineering, 68, pp. 113-120 (2015).

40. Campione, G., Colajanni, P., and Monaco, A. "Analytical evaluation of steel-concrete composite trussed beam shear capacity", Materials and Structures, 49(8), pp. 3159-3176 (2016).

41. Lu, X., Wang, D., and Zhao, B. "Experimental study on seismic performance of precast concrete shear wall with joint connecting beam under cyclic loadings", In Experimental Research in Earthquake Engineering, Springer, pp. 373-386 (2015).

42. Zhang, T., Visintin, P., and Oehlers, D.J. "Shear strength of RC beams with steel stirrups", Journal of Structural Engineering, $142(2)$, p. 04015135 (2016).

43. Adhikary, B.B. and Mutsuyoshi, H. "Artificial neural networks for the prediction of shear capacity of steel plate strengthened RC beams", Construction and Building Materials, 18(6), pp. 409-417 (2004).

44. Adhikary, B.B. and Mutsuyoshi, H. "Prediction of shear strength of steel fiber RC beams using neural networks", Construction and Building Materials, 20(9), pp. 801-811 (2006).

45. Abdalla, J.A., Elsanosi, A., and Abdelwahab, A. "Modeling and simulation of shear resistance of $\mathrm{R} / \mathrm{C}$ beams using artificial neural network", Journal of the Franklin Institute, 344(5), pp. 741-756 (2007). 
46. Zsutty, T. "Shear strength prediction for separate catagories of simple beam tests", In ACI Journal Proceedings, 68(2), pp. 138-143 (1971).

47. Nehdi, M., El Chabib, H., and Saïd, A.A. "Proposed shear design equations for FRP-reinforced concrete beams based on genetic algorithms approach", Journal of Materials in Civil Engineering, 19(12), pp. 10331042 (2007).

48. Ahn, N., Jang, H., and Park, D.K. "Presumption of shear strength of steel fiber reinforced concrete beam using artificial neural network model", Journal of Applied Polymer Science, 103(4), pp. 2351-2358 (2007).

49. Perera, R., Barchín, M., Arteaga, A., and De Diego, A. "Prediction of the ultimate strength of reinforced concrete beams FRP-strengthened in shear using neural networks", Composites Part B: Engineering, 41(4), pp. 287-298 (2010).

50. Tanarslan, H. "Predicting the capacity of RC beams strengthened in shear with side-bonded FRP reinforcements using artificial neural networks", Composite Interfaces, 18(7), pp. 587-614 (2011).

51. Tanarslan, H., Secer, M., and Kumanlioglu, A. "An approach for estimating the capacity of RC beams strengthened in shear with FRP reinforcements using artificial neural networks", Construction and Building Materials, 30, pp. 556-568 (2012).

52. Lee, S. and Lee, C. "Prediction of shear strength of FRP-reinforced concrete flexural members without stirrups using artificial neural networks", Engineering Structures, 61, pp. 99-112 (2014).

53. Nasrollahzadeh, K. and Basiri, M.M. "Prediction of shear strength of FRP reinforced concrete beams using fuzzy inference system", Expert Systems with Applications, 41(4), pp. 1006-1020 (2014).

54. Perera, R., Tarazona, D., Ruiz, A., and Martín, A. "Application of artificial intelligence techniques to predict the performance of RC beams shear strengthened with NSM FRP rods. Formulation of design equations", Composites Part B: Engineering, 66, pp. 162-173 (2014).

55. Tanarslan, H., Kumanlioglu, A., and Sakar, G. "An anticipated shear design method for reinforced concrete beams strengthened with anchoraged carbon fiberreinforced polymer by using neural network", The Structural Design of Tall and Special Buildings, 24(1), pp. 19-39 (2015).

56. Naderpour, H., Kheyroddin, A., and Amiri, G.G. "Prediction of FRP-confined compressive strength of concrete using artificial neural networks", Composite Structures, 92(12), pp. 2817-2829 (2010).

57. Naderpour, H., Kheyroddin, A., Amiri, G.G., and Hoseini Vaez, S.R. "Estimating the behavior of FRPstrengthened RC structural members using artificial neural networks", Procedia Engineering, 14, pp. 31833190 (2011).

58. Jafari, M., Mirrashid, M., and Vahidnia, A. "Prediction of chloride penetration in the concrete containing magnetite aggregates by adaptive neural fuzzy inference system (ANFIS)", 7th Internatinal Symposium on Advances in Science and Technology (5th sastech), Bandare Abbas, Iran (2013).

59. Mirrashid, M., Jafari, M., Akhlaghi, A., and Vahidnia, A. "Prediction of compressive strength of concrete containing magnetite aggregates by Adaptive Neural Fuzzy Inference System (ANFIS)", 4th Internatinal Conference on Concrete \& Development (ICCD), Tehran, Iran (2013).

60. Mirrashid, M. and Bigdeli, S. "Genetic algorithm for prediction the compressive strength of mortar containing wollastonite", 1st National Congress on Counstruction Engineering and Projects Assessment, Gorgan, Iran (2014).

61. Naderpour, H. and Mirrashid, M. "Application of soft computing to reinforced concrete beams strengthened with fibre reinforced polymers: A state-of-the-art review", in Computational Techniques for Civil and Structural Engineering, 38, Chapter 13, Saxe-Coburg Publications, Stirlingshire, UK, pp. 305-323 (2015).

62. Ahmadi, M., Naderpour, H., and Kheyroddin, A. "ANN model for predicting the compressive strength of circular steel-confined concrete", International Journal of Civil Engineering, 15(2), pp. 213-221 (2017).

63. Ilkhani, M., Moradi, E., and Lavasani, M. "Calculation of torsion capacity of the reinforced concrete beams using artificial neural network", Soft Computing in Civil Engineering, 1(2), pp. 8-18 (2017).

64. Mirrashid, M. "Comparison study of soft computing approaches for estimation of the non-ductile RC joint shear strength", Soft Computing in Civil Engineering, 1(1), pp. 12-28 (2017).

65. Naderpour, H. and Alavi, S. "A proposed model to estimate shear contribution of FRP in strengthened $\mathrm{RC}$ beams in terms of adaptive neuro-fuzzy inference system", Composite Structures, 170, pp. 215-227 (2017).

66. Naderpour, H., Khatami, S., and Barros, R. "Prediction of critical distance between two MDOF systems subjected to seismic excitation in terms of artificial neural networks", Periodica Polytechnica, Civil Engineering, 61(3), p. 516 (2017).

67. Naderpour, H. and Mirrashid, M. "Compressive strength of mortars admixed with wollastonite and microsilica", In Materials Science Forum, 890, pp. 415-418 (2017).

68. Naderpour, H. and Mirrashid, M. "An innovative approach for compressive strength estimation of mortars having calcium inosilicate minerals", Journal of Building Engineering, 19, pp. 205-215 (2018). 
69. Naderpour, H., Rafiean, A., and Fakharian, P. "Compressive strength prediction of environmentally friendly concrete using artificial neural networks", Journal of Building Engineering, 16, pp. 213-219 (2018).

70. Naderpour, H., Vahdani, R., and Mirrashid, M. "Soft computing research in structural control by mass damper (A review paper)", 4th International Conference on Structural Engineering, Tehran, Iran (2018).

71. Penelis, G.G. and Penelis, G.G. Concrete Buildings in Seismic Regions, CRC Press (2014).

72. Broo, H. "Shear and torsion in concrete structures", Gothenburg: Chalmers University of Technology (2008).

73. Jang, J.-S.R. "ANFIS: adaptive network based fuzzy inference systems", IEEE Trans Syst Man Cybern, 23(3), pp. 665-685 (1993).

74. Adeli, H. and Panakkat, A. "A probabilistic neural network for earthquake magnitude prediction", Neural Networks, 22(7), pp. 1018-1024 (2009).

75. Chiu, S.L. "Fuzzy model identification based on cluster estimation", Journal of Intelligent and Fuzzy Systems, 2(3), pp. 267-278 (1994).

76. Clark, A.P. "Diagonal tension in reinforced concrete beams", In ACI Journal Proceedings, 48(10), pp. 145156 (1951).

77. Bresler, B. and Scordelis, A.C. "Shear strength of reinforced concrete beams", In ACI Journal Proceedings, (1963).

78. Bresler, B. and Scordelis, A.C. "Shear Strength of Reinforced Concrete Beams: Series II", Institute of Engineering Research, University of California, Berkeley, CA 64-2 (1964).

79. Bresler, B. and Scordelis, A.C. "Shear Strength of Reinforced Concrete Beams: Series III", Institute of Engineering Research, University of California, Berkeley, CA 65-10 (1966).

80. Krefeld, W.J. and Thurston, C.W. "Studies of the shear and diagonal tension strength of simply supported reinforced concrete beams", In ACI Journal Proceedings, 63(4), pp. 451-476 (1966) .

81. Placas, A. and Regan, P.E. "Shear failure of reinforced concrete beams", In ACI Journal Proceedings, 68(10), pp. $763-773$ (1971).

82. Swamy, R. and Andriopoulos, A. "Contribution of aggregate interlock and dowel forces to the shear resistance of reinforced beams with web reinforcement", ACI Special Publication, 42, pp. 129-168 (1974).
83. Mattock, A.H. and Wang, Z. "Shear strength of reinforced concrete members subject to high axial compressive stress", In ACI Journal Proceedings, 81(3), pp. 287-298 (1984).

84. Mphonde, A.G. and Frantz, G.C. "Shear tests of highand low-strength concrete beams with stirrups", ACI Special Publication, 87, pp. 179-196 (1985).

85. Elzanaty, A.H., Nilson, A.H., and Slate, F.O. "Shear capacity of reinforced concrete beams using highstrength concrete", In ACI Journal Proceedings, 83(2), pp. 290-296 (1986).

86. Anderson, N.S. and Ramirez, J.A. "Detailing of stirrup reinforcement", Structural Journal, 86(5), pp. 507-515 (1989).

87. Sarsam, K.F. and Al-Musawi, J.M. "Shear design of high-and normal strength concrete beams with web reinforcement", Structural Journal, 89(6), pp. 658-664 (1992).

88. Xie, Y., Ahmad, S.H., Yu, T., Hino, S., and Chung, W. "Shear ductility of reinforced concrete beams of normal and high-strength concrete", Structural Journal, 91(2), pp. 140-149 (1994).

89. Yoon, Y.-S., Cook, W.D., and Mitchell, D. "Minimum shear reinforcement in normal, medium, and highstrength concrete beams", ACI Structural Journal, 93(5), pp. 576-584 (1996).

90. Frosch, R.J. "Behavior of large-scale reinforced concrete beams with minimum shear reinforcement", Structural Journal, 97(6), pp. 814-820 (2000).

91. Tompos, E.J. and Frosch, R.J. "Influence of beam size, longitudinal reinforcement, and stirrup effectiveness on concrete shear strength", ACI Structural Journal, 99(5), pp. 559-567 (2002).

92. Lee, J.-Y. and Hwang, H.-B. "Maximum shear reinforcement of reinforced concrete beams", ACI Structural Journal, 107(5), pp. 580-588 (2010).

93. Lee, J.-Y., Choi, I.-J., and Kim, S.-W. "Shear behavior of reinforced concrete beams with high-strength stirrups", ACI Structural Journal, 108(5), pp. 620-629 (2011).

\section{Biographies}

Hosein Naderpour received his $\mathrm{PhD}$ degree with high honors in Structural Engineering. He then joined Semnan University, where he is presently an Associate Professor of Structural Engineering. Since joining the faculty of Civil Engineering at Semnan University, Dr. Naderpour has taught a variety of undergraduate and graduate courses in the areas of structural en gineering, numerical methods, mechanics of materials, structural stability, concrete structures, structural reliability, and soft computing. Dr. Naderpour is the author of 60 papers published in journals and about 100 papers presented at national and international conferences. He 
has given several speeches in Switzerland, China, Australia, South Korea, Romania, Turkey, Canada, Hong Kong, Belgium, Portugal, Spain, Japan, Germany, Italy, Czech Republic, and France. He is currently a chief member of Iranian Earthquake Engineering Association, Iran Concrete Institute (ICI), Iranian Society for Light Steel Framing (LSF), Iran's National Elites Foundation, Safe School Committee, and Organization for Development, Renovation and Equipping Schools of Iran (DRES). Furthermore, he is currently the editorin-chief of two international journals in the area of civil and mechanical engineering including Journal of Soft Computing in Civil Engineering (SCCE) and Journal of Computational Engineering and Physical Modeling (CEPM). His major research interests include the application of soft computing in structural engineering, seismic resilience, structural reliability, structural optimization, and damage detection of structures.
Masoomeh Mirrashid received her $\mathrm{PhD}$ degree in Structural Engineering at the Semnan University, Iran. She earned the third rank and the highest rank in Civil and Structural Engineering among all graduates from Islamic Azad University, Iran, in BSc and MSc degrees, respectively. She has taught several courses of higher education including Theory of Elasticity and Plasticity, Dynamic of Structures, and Advanced Concrete and Steel Structures. She is Associate Editor for the Journal of Practice Periodical on Structural Design and Construction (publisher: ASCE) and also a reviewer of the journals of ASCE, Elsevier, Springer, Wiley, IEEE, and ASTM. Dr. Mirrashid is the author and co-author of several research publications including journal articles and international conference articles. Her fields of interest include structural engineering, earthquake, vulnerability, concrete, soft computing, fuzzy, and also neuro-fuzzy systems. 